\title{
Sintering and Reactive Sintering by Spark Plasma Sintering (SPS)
}

\author{
Giulia Franceschin, Nancy Flores-Martínez, \\ Gabriela Vázquez-Victorio, Souad Ammar and \\ Raul Valenzuela \\ Additional information is available at the end of the chapter \\ http://dx.doi.org/10.5772/intechopen.68871
}

\begin{abstract}
A wide variety of technological applications, especially in electronics, requires high-density nanostructured solids, consolidated by sintering from nanoparticles. A new sintering technique known as spark plasma sintering (SPS) appears as the only method to reach high densities while preserving the final grain size within the nanometric range, with the added advantage of carrying out the process at significantly lower temperatures and shorter times as compared with the classical processes. Recent studies have revealed that in many cases, SPS can also accomplish the solid-state reaction to achieve the desired compound, leading to reactive SPS (RSPS). In this chapter, a review of RSPS is presented, focusing particularly on magnetic oxide materials as functional solids.
\end{abstract}

Keywords: nanostructured solids, ceramic materials, reactive spark plasma sintering, solid-state processing, magnetic properties

\section{Introduction}

For the past two decades, the synthesis and applications of magnetic nanoparticles (MNPs) have gained immense interest in a wide range of technologies, especially in the biomedical field [1-4]. These applications are based on the novel magnetic properties associated with the nanoscale [5]. In the electronics field, nanostructured materials point also to innovative applications [6, 7], particularly in magnetic recording, actuators, and microwave devices. For these applications, however, a powder constituted by MNPs is not suitable; a high density, consolidated solid is required. Consolidation by classic sintering methods requires high 
temperatures and long times - more than $1000^{\circ} \mathrm{C}$ for several hours - to reach densities above $90 \%$. Such conditions lead to an excessive grain growth, which deteriorate the properties associated with the nanoscale, thus making such consolidation methods impractical.

Spark plasma sintering (SPS) [8] has recently been revealed as an extremely efficient sintering technique for consolidating nanopowders into high density, nanostructured materials. In practice, the powders are heated in a conductive SPS die at very high rates by the action of electric pulses and maintained under uniaxial pressure (Figure 1), leading to their sintering with impressive shorter times and lower temperatures than in conventional methods. In addition, to be a more efficient method, it allows a tight control of grain growth, thus permitting the production of nanostructured materials. The principle of SPS and convenient design of the facilities make it attractive for conducting materials. Recent results show, however, that it is equally powerful for nonconductive ones [9].

The current is applied and passed through the graphite die. If the sample is nonconductive, the heat generated inside the walls of the die assists in powder consolidation. If starting powders are a conductive material, the current goes through the powder, and the first sparks are in the surface atoms as well as in surface defects. This punctual warming of atoms is known as hot spots. In these zones, the temperature increases thousands of degrees in a very short time, and nucleation and grain growth begin. If the sample is an insulating phase, the electric field associated with the electric pulses has also a strong effect on atomic diffusion, and sintering is enhanced [9].

SPS has been recently examined in a much broader perspective and has gained a strong reputation as a versatile method of solid-state synthesis, not only for sintering, but also for solid-state reactions, as reported in relevant literature [11, 12]. SPS then becomes reactive SPS (RSPS).

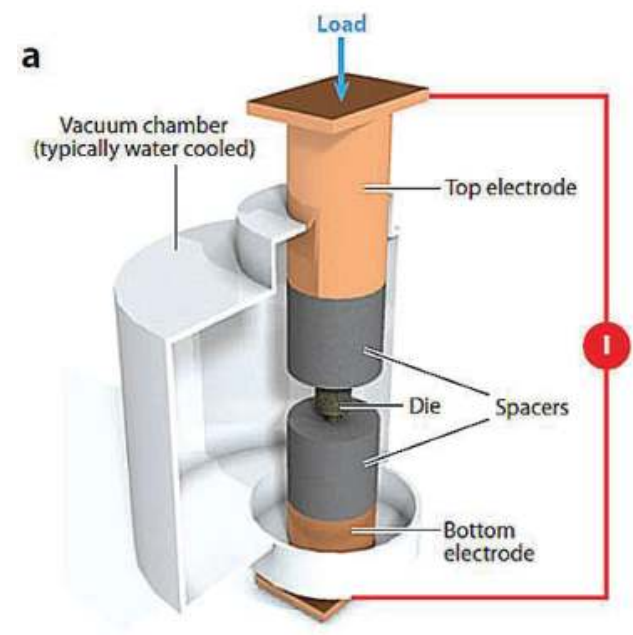

Figure 1. Schematics of the vacuum chamber, electrodes, and pressing die of the SPS system (adapted from Ref. [10]). 
In this review, we analyze the microstructure formation of the products of chemical reactions occurring in RSPS, in an attempt to directly produce nanostructured solids starting from the corresponding reactants, that is, an intermediate solid phase, or a mixture of precursors, containing the required elements to form the desired phase. We also discuss the possibility of fabricating nanocomposites, in which the interfaces between the constituting phases can be improved by particular tailoring.

Focusing on magnetic granular oxide nanostructures, we present successful syntheses with a special emphasis on their microstructure stability and attractive properties of the materials. We discuss the challenges of producing a dense nanostructured material when reaction and densification do not coincide during the SPS. Case examples in the fields of magnetocaloric materials (manganites), soft magnetic materials (garnets), and permanent magnets (hexaferrites) are specifically addressed.

We also discuss the limitations of such a technique, in relation to its reducing operating conditions and propose some alternatives to overcome main drawbacks. Indeed, RSPS is mainly performed using graphite-made die and punches under dynamic vacuum, creating a reducing atmosphere. In the case of oxide materials, this can lead to a partial reduction, sometimes even to a metal contamination, affecting the final physical properties of the consolidated solids (electric conductivity, for instance). The replacement of carbon dies by tungsten carbide in such materials offers an interesting alternative.

\section{Reduction reactions during SPS processes}

The composition of the environment inside the SPS chamber affects the material's diffusivity during sintering. For this reason, the processes that normally occur during a sintering cycle, such as phase constitution, densification, and grain growth, are strongly affected by the sintering atmosphere [13].

Typical materials developed by the SPS technique are refractory metals and intermetallics, oxide and nonoxide ceramics. The particles constituting the powders before consolidation tend to decrease their surface energy by desorption of chemical species, once introduced inside the SPS chamber. The released gas, water, or organic compounds in the atmosphere modify the thermodynamic driving force to surface reduction and sintering.

Commonly, the atmospheres employed for sintering are:

- Vacuum $\left(10^{-4}\right.$ to $10^{-5}$ bar $)$,

- Inert gas (up to 1.3 bar), or

- Reducing gas hydrogen-based mixtures.

The atmosphere composition inside the pressing tools which contain the sample may differ considerably from the atmosphere outside [9], making it difficult to control the sintering atmosphere. Sample reduction during RSPS occurs when the thermodynamic conditions 
are favorable to the imbalance of either one of the following reactions from the right to the left side:

$$
\begin{aligned}
& \text { metal }+\mathrm{O}_{2} \leftrightarrows \text { oxide }+\Delta \mathrm{H}^{0}{ }_{1} \\
& \text { metal }+2 \mathrm{H}_{2} \mathrm{O} \leftrightarrows \text { oxide }+2 \mathrm{H}_{2}+\Delta \mathrm{H}^{0}{ }_{2} \\
& \text { metal }+2 \mathrm{CO}_{2} \leftrightarrows \text { oxide }+2 \mathrm{CO}+\Delta \mathrm{H}^{0}{ }_{3}
\end{aligned}
$$

$\Delta H^{0}{ }_{1}, \Delta H^{0}{ }^{\prime}$ and $\Delta H^{0}{ }_{3}$ are the heat released per $\mathrm{O}_{2}$ mole in each oxidizing reaction (from left to right side). By definition, we can calculate the corresponding changes of free enthalpy:

$$
\begin{aligned}
& \Delta G_{1}^{0}=-\Delta H_{1}^{0}=-R T \ln \left(\frac{P_{\text {metal }}}{P_{\text {oxide }}} \cdot P_{O_{2}}\right) \\
& \Delta G_{2}^{0}=-\Delta H_{2}^{0}=-R T \ln \left(\frac{P_{\text {metal }}}{P_{\text {oxide }}} \cdot \frac{P_{H_{2} O}^{2}}{P_{H_{2}}^{2}}\right) \\
& \Delta G_{3}^{0}=-\Delta H_{3}^{0}=-R T \ln \left(\frac{P_{\text {metal }}}{P_{\text {oxide }}} \cdot \frac{P_{\text {CO }}^{2}}{P_{\text {CO }}^{2}}\right)
\end{aligned}
$$

A standard measure for the tendency of a metal (or a chemical element) to oxidize is given by Eqs. (4)-(6) when $P_{\mathrm{O} 2}=1$; thus, we obtain Eq. (7), which is the heat released when 1 mole of $\mathrm{O}_{2}$ gas at $1 \mathrm{~atm}$ pressure combines with 1 mole of metal to form the oxide in function of temperature $T$ :

$$
\Delta G^{0}=-R T \ln \left(\frac{P_{\text {metal }}}{P_{\text {oxide }}}\right)
$$

The graphic representation of $\Delta G^{0}=f(T)$ is known as the Ellingham-Richardson diagram (Figure 2). It allows the direct evaluation of the relative affinity between the elements and the oxidizing agent. Elements with a lower line in $\Delta G^{0}$ in the diagram have a greater affinity to oxygen. This diagram is useful to understand the thermodynamics of the reactions between the sintering material and the atmosphere, and it can give information about the dissociation temperature, the dissociation pressure, and the effect of reducing agents [14].

Special attention must be given to the pressing tools' material. Standard pressing tools used in the RSPS process are graphite based, often internally covered with carbon sheets or foils, in order to ease the removal of the sample after sintering [15]. Thus, graphite components are in close contact with the sample and can become reactive with the oxygen eventually present in the sample itself at temperatures higher than $600^{\circ} \mathrm{C}$. Other sources of oxygen are moisture or other gases in the sintering atmosphere. Such a chemical reaction causes the formation of $\mathrm{CO}$ and a continuous decrease of the oxygen partial pressure within the furnace, creating a reducing condition in the 


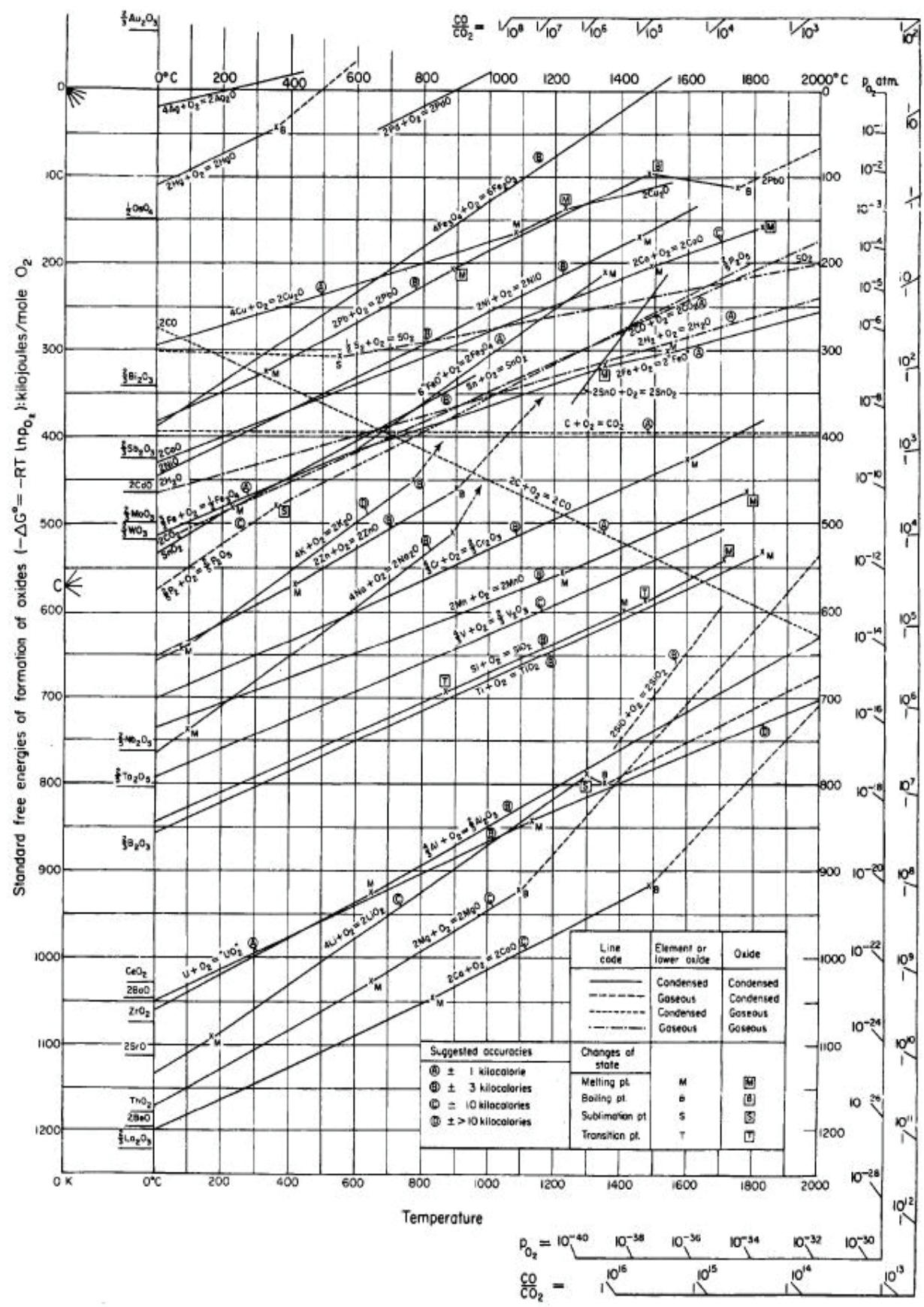

Figure 2. Ellingham-Richardson diagram [16]. 
sintering atmosphere. When an intense gas phase transport is established between the sample and the mold, reduction of oxides or even precipitation of carbon or carbide in the sample may occur [9].

The materials obtained by the RSPS technique can be distinguished into two main categories in relation to their affinity to reductive atmosphere: (a) if oxide reduction is a desirable effect and (b) if reduction is a secondary effect that should be avoided during the ceramic formation. Metals and nonoxide ceramics constitute the first class of materials, while oxide ceramics represent the second one.

For metals and nonoxide ceramics, reductive atmospheres, such as inert gas or reducing hydrogen gas mixture, are suggested during sintering, because they are effective on cleaning the oxide naturally formed on the metallic surface of the starting powder during air exposition.

The benefit of oxide reduction in this kind of materials is related to the possibility to enhance the sample densification; in fact, oxide compounds possess a smaller density than the corresponding metal, and they hinder atomic diffusion during the densification step.

Such a reductive atmosphere has also been suggested for ultra-high-temperature ceramics (UHTC) to promote their densification. Sometimes, specific additives are mixed to the starting powder to promote reduction and thus enhance densification. For instance, $\mathrm{C}$ or $\mathrm{B}_{4} \mathrm{C}$ has been used as additives in $\mathrm{TaC}$ densification [17], while $\mathrm{MoSi}_{2}, \mathrm{TaSi}_{2^{\prime}}$ and $\mathrm{SiC}$ have been considered as additives for oxygen removal during $\mathrm{HfB}_{2}$ sintering [18-20].

Systems requiring a reductive atmosphere during their reactive consolidation are oxide/ metal nanocomposites. In practice, the reductive atmosphere can be specifically used for the in-situ formation of metal component. As an example, $\mathrm{Al}_{2} \mathrm{O}_{3} / \mathrm{Ni}$ granular solids were produced by reacting and sintering a mixture of $\mathrm{Al}_{2} \mathrm{O}_{3}$ and $\mathrm{NiO}$ powders inside a carbon die [15].

For functional oxide ceramics, including magnetics, reducing sintering atmosphere may have dramatic consequences on the final properties. It may modify the starting oxide composition. Typically, it generates oxygen vacancies, which in the case of transparent ceramics, such as yttrium-aluminum-garnet (YAG), induces light absorption and in-line transmission decrease [21]. In the case of ferromagnetic $p$-doped manganite ceramics, the formed oxygen vacancies decrease the average oxidation state of the paramagnetic manganese cations, inducing a net reduction of the Curie temperature of the final solid in comparison to its conventionally made bulk counterpart [22]. In Ni-Zn ferrite, a well-known resistive soft magnet, consolidation by SPS involves a $\mathrm{Fe}^{3+}$ into $\mathrm{Fe}^{2+}$ reduction inside the ferrite grains compensated by a loss of $\mathrm{Ni}$ cations, which precipitate as $\mathrm{Ni}$ metal between the grains, increasing the total electrical conductivity [23].

As a consequence of oxide ceramic changes in reductive atmospheres, solutions to the tools' reactivity at high temperature have been considered. In other words, when the control of the atmosphere is not enough to avoid secondary reduction reactions, new tool materials have been employed. Graphite reinforced with carbon fiber dies [24] is suitable 
for high-pressure sintering, because of their high mechanical resistance to compression; the possibility to increase the pressure applied to pistons during consolidation allows to operate the process at even lower temperature, thus limiting the possibility of reaction between carbon and oxide inside the material. Tungsten carbide, steel, and refractory metals, such as molybdenum alloys, copper-beryllium, and alumina [25], have been also used as conductive sintering tools. Double-walled tools with inner ceramic die and outer graphite mantle have been also employed [26]. Some works report the use of layers and foils of alumina or other different metals, such as molybdenum, tungsten, and tantalum, which are introduced inside the graphite die to cover the internal mold walls before introducing the sample [9]. By these less-costly operating conditions, the sintering material is never in contact with graphite.

\section{Effects of current and pressure}

\subsection{Electrical current effect}

In addition to heating, the effect of current pulses is to enhance mass transport during sintering, more specifically by one of the three mechanisms [27]: (a) increasing the point defect concentration; (b) a reduction in the activation energy for mobility of defects; or (c) electron wind modification of the diffusion flux (electromigration).

Temperature and current are not independent parameters; high heating rates are achieved by increasing pulsed direct current. This is the major difference between the conventional hot-pressing and the SPS methods; in the RSPS method, both the die (typically graphite) and the sample are heated by Joule mechanism from a current passing through them (if the sample is conducting) [27]. Nonconductive materials are heated by means of heat conduction from the die walls. Pulsed direct current can enhance the reaction kinetics when the reactants are brought to interact in the SPS. This effect is, however, system dependent [28]. A change in the electrical conductivity of the materials in the die as reaction progresses can give rise to undesired results. Schmidt et al. [29] studied the decomposition behavior of $\mathrm{MgH}_{2}$ in RSPS; in order to increase electrical conductivity, graphite was added to the $\mathrm{MgH}_{2}$ powder. Metallic magnesium, the product of decomposition, increases the electrical conductivity of the material in the SPS die. This example shows that as the reaction product accumulates, the conductivity of the material in the sintering die changes; if it increases, the reaction is self-enhanced due to the presence of in-situformed conductive particles inducing the formation of hot spots in the remaining, not yet fully reacted, mixture.

In the case of silica-doped yttria-stabilized zirconia sintering, the electrical resistivity of grain boundaries is often increased by the presence of impurity phases of siliceous compounds. SPS allowed a significant reduction in these compounds while leaving the grains unaffected [31]. This effect was attributed to the generation of electrical discharges between particles as the SPS electrical pulses are applied. The discharges expel the liquid silica phase to triple points in grain boundaries, thus reducing their effects on resistivity. 


\subsection{Pressure effect}

Mechanically, the pressure has a direct effect on particle rearrangement and the destruction of agglomerates, particularly in the case of nanometric powders. However, the significance of the pressure on sintering depends on the particle size. When the particle size is small, the relative contribution of the pressure is small but becomes significant as the particle size increases [27]. In a study on the sintering of nanometric pure zirconia, Skandan et al. [30] found that the pressure had no effect on the relative density of fine-grained powder $(6 \mathrm{~nm})$ up to a pressure of about $35 \mathrm{MPa}$; in contrast, the density increased sharply when higher pressure

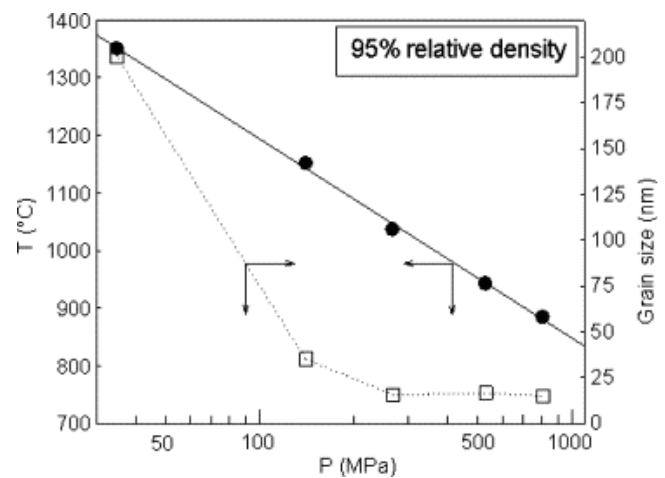

Figure 3. Relationship between hold temperature and the applied pressure required to obtain samples with a relative density of $95 \%$ in the case of nanometric fully stabilized zirconia $\left(8 \% \mathrm{Y}_{2} \mathrm{O}_{3}\right)$. Hold time: $5 \mathrm{~min}$. The grain size of the materials is also shown [30].

was used. For larger particle size powder $(12 \mathrm{~nm})$, the same behavior was observed except that the transition occurred at about $10 \mathrm{MPa}$. Another result of the application of pressure is a decrease in the sintering temperature. For the case of SPS densification of a nanometric cubic zirconia, Anselmi-Tamburini et al. [27] showed that the combination of fast heating rate and high pressure produces a marked reduction in the sintering temperature. Figure 3 shows the effect of pressure on the sintering temperature required to obtain a $95 \%$ relative density (with 5 -min hold time). The figure also shows the grain size obtained under these conditions. The temperature required to achieve $95 \%$ of density decreases linearly with the logarithm of the applied pressure. The grain size varied from about 200 to $15 \mathrm{~nm}$.

\section{Precursors}

\subsection{Size of precursors}

The size of precursors plays an important role in the final consolidates. In this manner, densification hinges on the characteristics of initial powders inside the die. As mentioned by 
Nygren [32], the grain growth is deeply related with the size of starting powder. When nanometric size precursors are employed, most of the driving force to reduce specific area is destined to the densification process.

In the case of micrometric precursors, pressure can enhance densification by four mechanisms [33]: particle rearrangement, localized deformation, bulk deformation, and neck growth. For large particle size of precursors $(45-90 \mu \mathrm{m})$, density is enhanced through particle rearrangement and localized deformation. In contrast, neck growth increases for smaller size of precursors $(\sim 25 \mu \mathrm{m})$, while bulk deformation has no influence [33].

Grains can keep the memory of the synthesis process by which they were made, and their characteristics are retained even in the sintered particles [34]. During the processing of $\mathrm{Al}_{2} \mathrm{TiO}_{5}$ by RSPS, varying the initial powder size and the nature of precursors could enhance consolidation, particularly for sol-gel and co-precipitation synthesis [34]. Co-gelified alumina-titania powders and mechanical mixtures of alumina and titania (both obtained by sol-gel method) and alumina-titania powders (recovered by co-precipitation method) were treated thermally before the RSPS process. The grain sizes for the powders synthesized by sol-gel and co-precipitation method were 10 and $50 \mathrm{~nm}$, respectively. Experimental conditions were the same for all the three samples during RSPS process. The final report showed a smaller increase in the grain size $(0.5 \mu \mathrm{m})$ for the consolidated powders synthesized by sol-gel as compared with the co-precipitated powders $(8 \mu \mathrm{m})$. However, the final density for the co-gelified alumina-titania and alumina titania initial powders was very close to the theoretical density $\left(3.7 \mathrm{~g} / \mathrm{cm}^{3}\right)$. Finally, the full phase of $\mathrm{Al}_{2} \mathrm{TiO}_{5}$ was obtained in co-gelified alumina-synthesized sample.

Different size and aggregation states of polyol-made $\mathrm{CoFe}_{2} \mathrm{O}_{4}$ starting powders were consolidated in similar conditions [35]. In the RSPS process, monodispersed initial powders around $5 \mathrm{~nm}$, and clusters of $\sim 50 \mathrm{~nm}$ (made also of $\sim 5 \mathrm{~nm}$ particles) were rapidly heated to $600^{\circ} \mathrm{C}$ for $6 \mathrm{~min}$ before rapid cooling. Unexpectedly, the final grain size resulted larger for the monodispersed precursor than for the clustered case. This difference was interpreted on the basis that grain growth is an essentially surface process, and in the monodispersed case, particles offered a larger free surface than in the clustered case.

\subsection{Nature of precursors}

Preliminary works exploring the possibility of preparing nanostructured manganite ceramics by the RSPS process have evidenced the role of the precursor's nature. Starting from a mixture of raw bulk oxides required a higher reacting and sintering temperature, while starting from a mixture of their hydroxide counterparts allowed a decrease in this operating parameter. Typically, $\mathrm{La}_{0,85} \mathrm{Na}_{0,15-\mathrm{x}} \mathrm{K}_{x} \mathrm{MnO}_{3}$ ceramics were prepared by RSPS starting from the $\mathrm{La}(\mathrm{OH})_{3}, \mathrm{Na}(\mathrm{OH})$, $\mathrm{K}(\mathrm{OH})$, and $\mathrm{MnO}_{2}$ commercial powder mixture, working at $800^{\circ} \mathrm{C}$ under a uniaxial pressure of 50 MPs for a couple of minutes (Figure 4a) [12]. In contrast, ceramic $\mathrm{LaMnO}_{3}$ was obtained by RSPS starting from $\mathrm{La}_{2} \mathrm{O}_{3}$ and $\mathrm{Mn}_{2} \mathrm{O}_{3}$ commercial powder mixture, working at $1000^{\circ} \mathrm{C}$ under the same pressure for almost the same sintering time (Figure $4 \mathrm{~b}$ ) [42]. The final density of both ceramics exceeded $90 \%$ of the theoretical value, and their average grain size was in the submicrometer range, the finest grains being obtained at the lowest sintering temperature of course. 

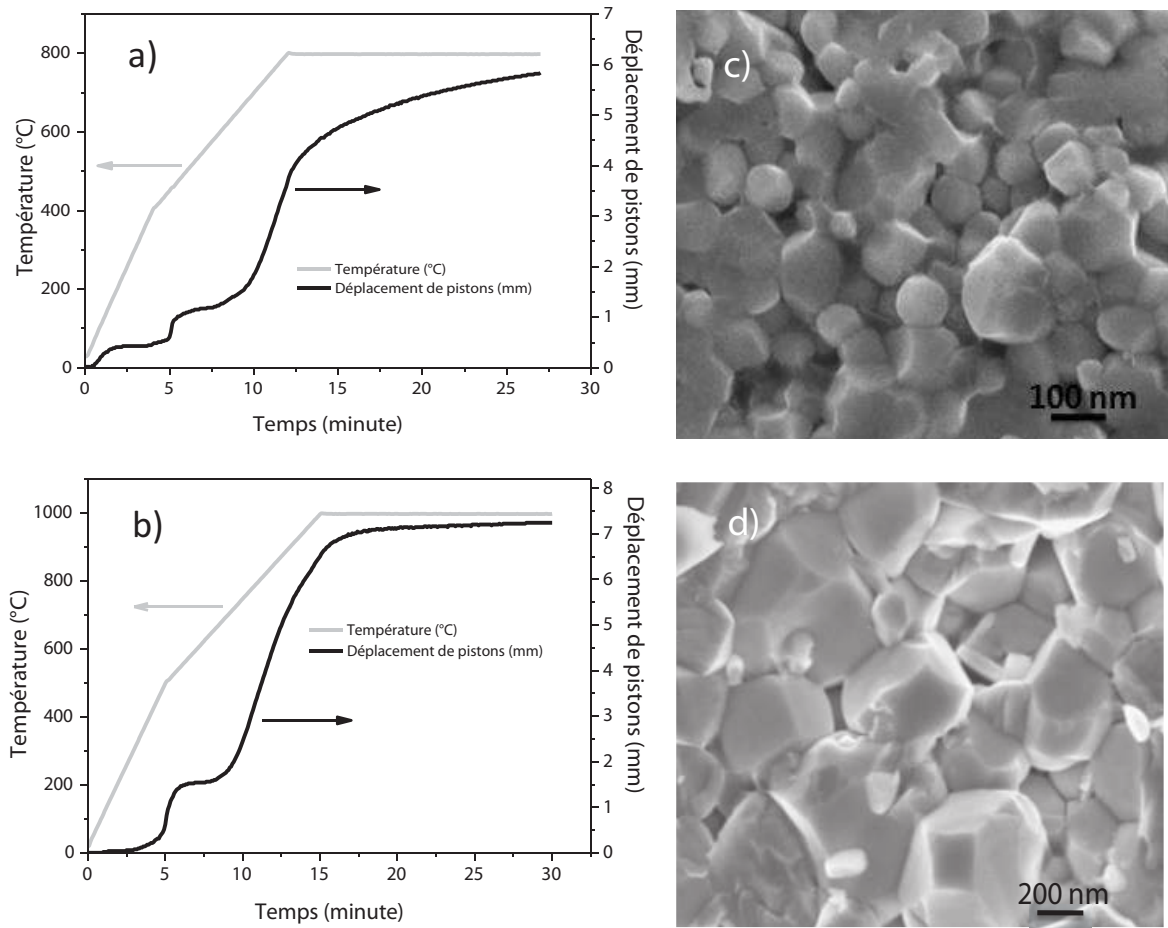

Figure 4. Shrinkage curve (temperature and piston displacement as a function of time) recorded during the RSPS process of $\mathrm{La}_{0.85} \mathrm{Na}_{0.15} \mathrm{MnO}_{3}$ (a) and $\mathrm{LaMnO}_{3}$ (b) ceramics and representative SEM micrographs of each ceramic (c and d, respectively) (adapted from Ref. [42]).

Starting from a mixture of raw oxides assisted by ball milling has been extensively used for the mechanical activation of the reactive powders before SPS treatment [36-38]. In order to achieve high-density ceramics with low SPS temperatures, a small particle size and high reactivity must be taken into consideration [39]. As an example, $\mathrm{Ni}_{0.5} \mathrm{Zn}_{0.5} \mathrm{Fe}_{2} \mathrm{O}_{4}$ ferrite was prepared by Song et al. [40]. Stoichiometric quantities of $\mathrm{NiO}, \mathrm{ZnO}$, and $\mathrm{Fe}_{2} \mathrm{O}_{3}$ were milled in a high-energy planetary ball mill. Different parameters of the grinding time were varied, for example 10, 20, and $40 \mathrm{~h}$, at a speed of $400 \mathrm{rpm}$. As expected, they found the higher the grinding time, the smaller the average size for the starting powders $(<100 \mathrm{~nm})$. For the sintering process, they selected the powders with $40 \mathrm{~h}$ milling time and particle size below 100 $\mathrm{nm}$. Different temperatures were chosen $\left(850,875,900\right.$, and $\left.925^{\circ} \mathrm{C}\right)$ for $5 \mathrm{~min}$, a pressure of 48 $\mathrm{MPa}$ and 5-min vacuum were applied. The best densification result was obtained at $925^{\circ} \mathrm{C}$. A density of $5.23 \mathrm{~g} / \mathrm{cm}^{3}$, corresponding to $99 \%$ of the theoretical value, was reached. No secondary phases were detected in structural characterization. Zehani et al. [41] studied NiZnCu ferrite at several grinding times and speeds. The stoichiometric proportions of precursor oxides ( $\mathrm{NiO}, \mathrm{Fe}_{2} \mathrm{O}_{3}, \mathrm{CuO}, \mathrm{ZnO}$ ) were ground in a planetary mill. RSPS was then performed at different temperatures and holding times, using a graphite die and working under argon 
atmosphere. The main conclusion was that the final particle size increased with increasing milling speed. Also, in milling times shorter than $2 \mathrm{~h}$ at $800 \mathrm{rpm}$, the lattice parameter variation was insignificant.

Amorphous or poorly crystallized intermediate solid phases obtained by soft chemistry, combining precipitation in a liquid solution and moderate annealing, and containing all the desired elements were also used to form highly dense and fine-grained oxide ceramics. This is for instance the case of $\mathrm{La}_{0.65} \mathrm{Ca}_{0.20} \mathrm{Na}_{0.15} \mathrm{MnO}_{3}$ manganite [43] and $\mathrm{Y}_{3} \mathrm{Fe}_{5} \mathrm{O}_{12}$ garnet [49] ceramics. The precipitated solids were first annealed at 600 and $400^{\circ} \mathrm{C}$, respectively, to remove the main noninorganic species in the form of $\mathrm{H}_{2} \mathrm{O}$ and $\mathrm{CO}_{2}$, and then SPS treated at a temperature of 700 and $750^{\circ} \mathrm{C}$, respectively, to obtain highly dense and fine-grained ceramics.

\section{RSPS-made magnetic ceramics: Synthesis and properties}

\subsection{Soft magnets: Garnets}

Magnetic garnets possess the crystal structure of mineral $\mathrm{Mn}_{3} \mathrm{Al}_{2} \mathrm{Si}_{3} \mathrm{O}_{12^{\prime}}$, with rare-earth (RE) and $\mathrm{Fe}^{3+}$ cations instead, leading to the general formula $\mathrm{RE}_{3} \mathrm{Fe}_{5} \mathrm{O}_{12}$, $\mathrm{RE}$ is in the series from $\mathrm{La}^{3+}$ to $\mathrm{Lu}^{3+}$. One of the most studied phases is the yttrium iron garnet (YIG), which is a remarkable ferrimagnetic material with many applications in microwave [44], magnetooptical [45], and spintronic devices [46], most of them based on the fact that YIG has the smallest linewidth for ferromagnetic resonance (FMR) [44]. Its ferrimagnetism results from

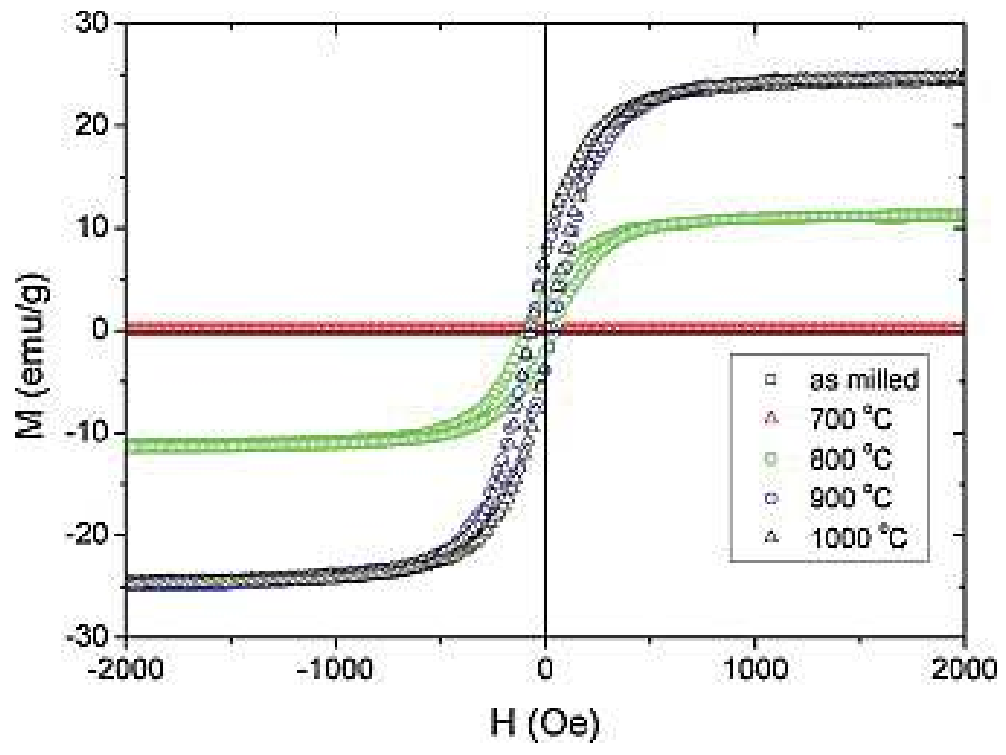

Figure 5. Hysteresis loops of ball-milled mixtures of iron and yttrium oxide for $5 \mathrm{~h}$ and annealed for $3 \mathrm{~h}$ at different temperatures (adapted from Ref. [48]). 
superexchange interactions [55] between octahedral and tetrahedral $\mathrm{Fe}^{3+}$ cations, which are antiparallel. As a bulk, YIG is commonly prepared by the classic solid-state reaction technique which involves temperatures as high as $1350^{\circ} \mathrm{C}$, for a few hours [47].

Nanostructured YIG (or other garnet) is typically prepared by combining soft chemistry, or ball milling, and annealing to complete the reaction before SPS sintering. This garnet crystal structure possesses a relatively large unit cell (160 atoms), making it difficult to achieve its synthesis at low temperature. A typical procedure can be high-energy ball milling of $\mathrm{Fe}_{2} \mathrm{O}_{3}$ $+\mathrm{Y}_{2} \mathrm{O}_{3}$ oxide reagents, followed by thermal annealing before SPS treatment [48]. The magnetization of the recovered annealed powders increases with the increase in the annealing temperature, and it approaches its bulk value, namely $28 \mathrm{emu} / \mathrm{g}$, only by samples annealed at $T \geq 900^{\circ} \mathrm{C}$ (Figure 5).

RSPS offers an excellent alternative to produce consolidated nanostructured YIG at low temperatures and very short sintering times. A convenient YIG precursor can be prepared by hydrolysis in a polyol method, followed by processing by RSPS to obtain a nanostructured garnet phase [49], with the general magnetic properties of bulk YIG. The intermediate solid phase is amorphous (Figure 6) with the required $\mathrm{Y} / \mathrm{Fe}$ stoichiometric ratio. Its preannealing at a temperature of $400^{\circ} \mathrm{C}$ allows its decomposition and the removal of main organic contents, but it is unsuitable to form the desired garnet phase. A reaction/sintering RSPS treatment at $750^{\circ} \mathrm{C}$ for 15 min produced a nanostructured solid with high density and nanosize grains. XRD-resolved patterns, Figure 6, showed that an amorphous phase leads first to the orthoferrite $\mathrm{YFeO}_{3}$ phase $\left(600-650^{\circ} \mathrm{C}\right)$ and then the transformation to the garnet $\mathrm{Y}_{3} \mathrm{Fe}_{5} \mathrm{O}_{12}$ phasefrom $750^{\circ} \mathrm{C}$.

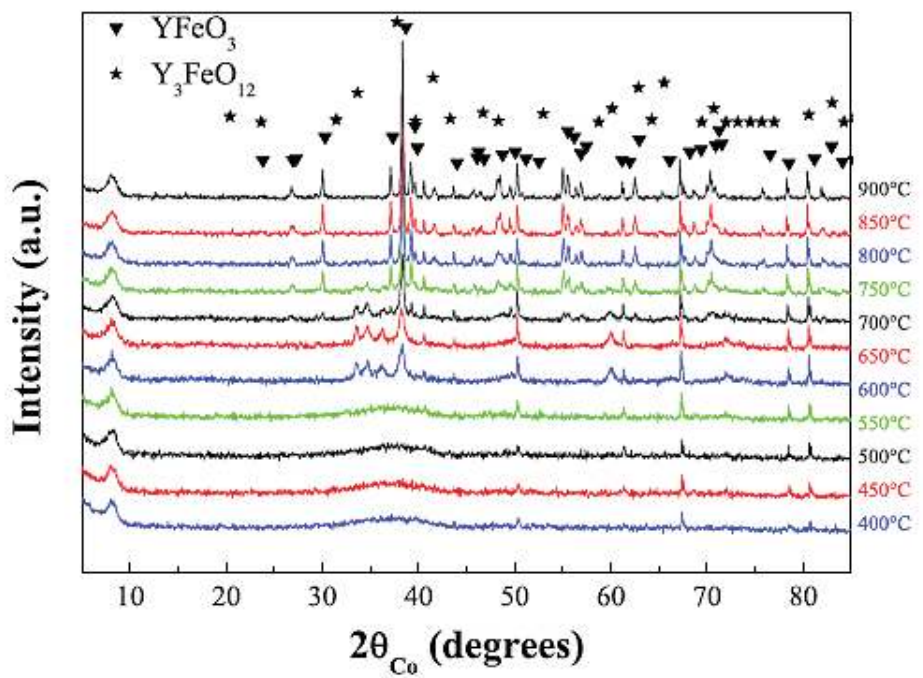

Figure 6. Temperature-resolved X-ray diffraction patterns of the polyol-synthesized YIG precursor. At about $600^{\circ} \mathrm{C}$, yttrium orthoferrite $\left(\mathrm{YFeO}_{3}\right)$ is formed, which then transforms into $\mathrm{YIG}$ at higher temperatures [49]. 
Interestingly, the resulting dense and submicrometer-grain-sized ceramic exhibited the same magnetic properties as the conventionally made bulk counterpart: a saturation magnetization of $28 \mathrm{emu} / \mathrm{g}$ and a coercive field close to zero at room temperature. Clearly, the reduction of the grain size from the micrometer size range to the submicrometer one does not introduce major magnetic changes, the surface-to-volume atomic fraction remaining negligible in both cases to induce significant magnetic changes.

\subsection{Magnetocalorics: Manganites}

$P$-doped manganite $\mathrm{Ln}_{1-\mathrm{x}} \mathrm{X} \mathrm{MnO}_{3}$ (Ln: trivalent rare-earth ion; $\mathrm{X}$ : monovalent alkaline, or divalent alkaline-earth cation) phases with the perovskite structure have been extensively studied over the last 15 years in view of their remarkable physical properties, which can be used for a wide variety of applications, particularly for giant magnetoresistance devices and magnetocalorics [50-53]. The correlation between magnetic and transport properties are interpreted on the basis of double exchange (DE) mechanism [54], the superexchange (SE) interactions [55], the electron-phonon coupling due to the Jahn-Teller effect of $\mathrm{Mn}^{3+}$ ions, and the magnetic-phase separation [51]. The undoped stoichiometric $\mathrm{LaMnO}_{3}$ compound, containing only $\mathrm{Mn}^{3+}$ ions is an insulating antiferromagnet [56], while doped ones contain $\mathrm{Mn}^{3+}$ and $\mathrm{Mn}^{4+}$ ions and may be ferromagnetic conductors. The magnetic properties of the former are driven by SE interactions, while those of the latter are mainly due to DE interactions. Consequently, the

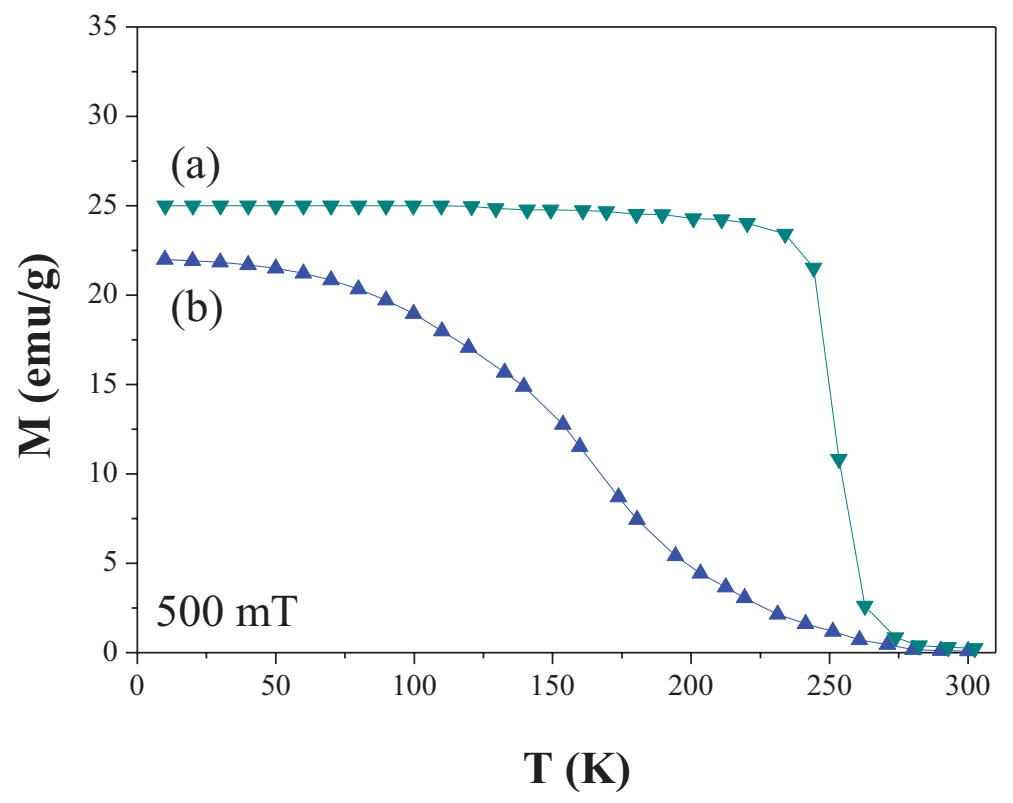

Figure 7. Temperature dependence of magnetization at $50 \mathrm{mT}$ of $\mathrm{La}_{0.70} \mathrm{Ca}_{0.30} \mathrm{MnO}_{3}$ ceramic produced by (a) conventional solid-state route at $1300^{\circ} \mathrm{C}$ and (b) by RSPSP at $800^{\circ} \mathrm{C}$ (adapted from Ref. [59]). 
atomic $\mathrm{Mn}^{4+} / \mathrm{Mn}^{3+}$ ratio is a key parameter in the achievement of the magnetoelectrical properties of these oxides.

To date, RSPS was successfully used to produce various manganite solid solutions, starting from raw oxides or hydroxides annealed at $800-1000^{\circ} \mathrm{C}$ under an uniaxial pressure of $50 \mathrm{MPa}$ and under vacuum: $\mathrm{LaMnO}_{3}$ [42], $\mathrm{La}_{0,85} \mathrm{Na}_{0,15} \mathrm{MnO}_{3}$ [57], $\mathrm{La}_{0,85} \mathrm{Na}_{0,15-x} \mathrm{~K}_{x} \mathrm{MnO}_{3}$ [12], $\mathrm{La}_{0.67} \mathrm{Ca}_{0.33} \mathrm{MnO}_{3}$ [58], and $\mathrm{La}_{0.7 \mathrm{a}} \mathrm{Ca}_{0.30-\mathrm{x}} \mathrm{Ba}_{\mathrm{x}} \mathrm{MnO}_{3}$ [59] among others. Interestingly, all the produced ceramics exhibited high densities over $90 \%$ of the theoretical values and submicrometer grain size, and a systematically broadened paramagnetic-to-ferromagnetic transition as a function of temperature, with a decreased Curie temperature $\left(T_{C}\right)$ value (Figure 7). These changes are due to an evolution of the chemical composition concerning the synthesis conditions. The conventionally made ceramics are assumed to be chemically homogeneous with a $\mathrm{Mn}^{4+} / \mathrm{Mn}^{3+}$ atomic ratio fixed by the doping rate, while the RSPS-made ones may suffer from heterogeneities related to their very rapid reacting/sintering kinetics. These heterogeneities can be associated to a $\mathrm{Mn}^{4+}$ concentration variation between the ceramic core and its surface in contact with graphite during RSPS experiments, with a total $\mathrm{Mn}^{4+} / \mathrm{Mn}^{3+}$ atomic ratio smaller than its theoretical value. This discrepancy was confirmed by K-Mn edge X-ray absorption spectroscopy (XANES) and iodometry chemical analysis and related to the reductive SPS processing conditions [58].

To evaluate the magnetocaloric properties of manganites, the variation of the magnetic entropy upon a given magnetic field change, $\Delta M$, is usually inferred from the first magnetization curves and plotted as a function of the temperature around $T_{C}$ value. $\Delta M(T)$ of RSPS-processed manganites is systematically much more broadened than that of their conventionally made ceramics (Figure 8) for the reasons given above. The commercial applications require a magnetocaloric effect extending on a broad temperature range. RSPS ceramics may just offer such an opportunity.
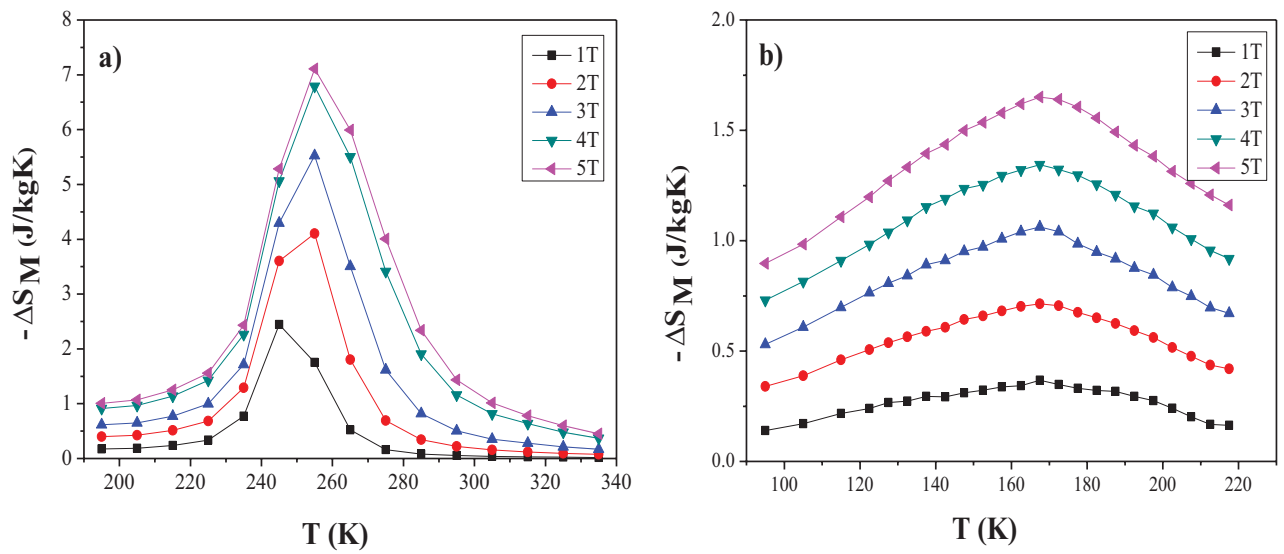

Figure 8. Magnetic entropy variation $\Delta S_{M}$ as a function of the temperature for a magnetic field change of 1, 2, 3, 4, and 5T $\mathrm{La}_{0.70} \mathrm{Ca}_{0.30} \mathrm{MnO}_{3}$ ceramic produced by conventional solid-state route at $1300^{\circ} \mathrm{C}$ (a) and by RSPS at $800^{\circ} \mathrm{C}$ (adapted from Ref. [59]). 


\subsection{Hard magnets: Hexaferrites}

Hexaferrites have become extremely important materials since they have a large variety of applications due to their high magnetocrystalline anisotropy in relation with their $\Delta M$ hexagonal structure. Their magnetic properties are mainly driven by SE interactions as most of insulating oxides. Technologically speaking, hexaferrites are mainly used in the form of bulk solids as permanent magnets in magnetic recording and magnetic data storage devices, and more recently, as systems operating at microwave/GHz frequencies [60].

As nanopowders, hexaferrites can be produced by different methods such as sol-gel [61], hydrothermal [62], aerosol pyrolysis [63], or mechanochemical synthesis [64]. In most of the cases, a subsequent annealing is required to provide enough energy to complete phase formation and an SPS sintering is needed to achieve their consolidation.

To the best of our knowledge, the RSPS process has been scarcely used to produce consolidated nanostructured hexaferrites. Bolarín-Miró et al. [65] carried out a comparative study between M-type strontium hexaferrite prepared from strontium and iron single oxides mechanically activated by high-energy ball milling for $5 \mathrm{~h}$ followed by RSPS, and the same milled powder mixture sintered by conventional route. They showed that, in comparison with conventional heat treatment, RSPS process allows the formation of strontium hexaferrite single phase at lower temperatures with a higher magnetization. In contrast, the resulting ceramics exhibited smaller coercive field (Figure 9).

Stingaciu et al. [66] reported the preparation of strontium hexaferrite by SPS starting also from ball-milling-activated commercially available $\mathrm{SrFe}_{12} \mathrm{O}_{19}$ powder. They observed that the hexaferrite phase is maintained during the milling process ( 8 to $42 \mathrm{~h}$ ), while it is not during the SPS treatment. Due to the reductive operating conditions, a nonnegligible amount of magnetite is formed leading to the production of a $\mathrm{SrFe}_{12} \mathrm{O}_{19}-\mathrm{Fe}_{3} \mathrm{O}_{4}$ nanocomposite. Moreover, they evidenced a pronounced decrease in the room-temperature coercive field $\left(H_{c}\right)$ and an increase

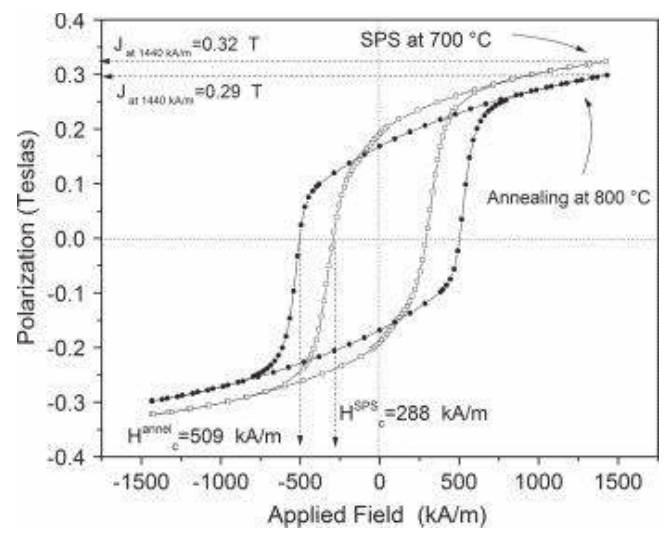

Figure 9. $J(H)$ Hysteresis loops of precursor's mixtures milled for $5 \mathrm{~h}$ and (a) pressed at $800 \mathrm{MPa}$ and annealed at $800^{\circ} \mathrm{C}$ (circle) and (b) SPS-treated at $700^{\circ} \mathrm{C}$ under $80 \mathrm{MPa}$ (square) (adapted from Ref. [65]). 
in the magnetization (Ms) at maximum applied field of $1 \mathrm{~T}$, for powders milled for a longer time and consolidated (Figure 10). They concluded that the magnetic properties of the studied nanocomposites are largely conditioned by the extrinsic properties of the secondary phase,

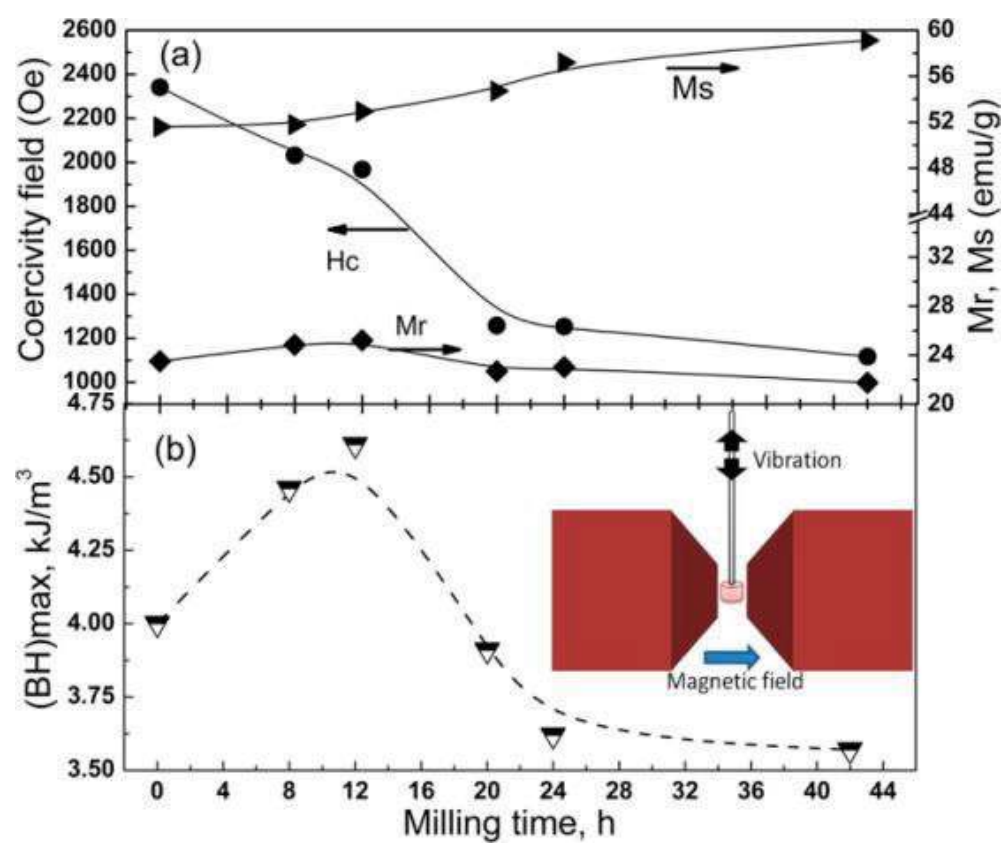

Figure 10. Evolution of the coercive field $H c$ (a), the remanent magnetization $\mathrm{Mr}$ (a), the magnetization at maximum applied field $1 \mathrm{~T}, \mathrm{Ms}$, and the maximum magnetic energy product $(B H)_{\max }$ of SPS-consolidated $\mathrm{SrFe}_{12} \mathrm{O}_{19}$ powder after different milling times. These data obtained from the hysteresis loops recorded at room temperature, applying the external magnetic field perpendicular to the uniaxial SPS pressing direction [66].

$\mathrm{Fe}_{3} \mathrm{O}_{4}$, a soft ferrimagnet, formed after the SPS, rather than the hard $\mathrm{SrFe}_{12} \mathrm{O}_{19}$ phaseparticlesize-reduction effect. Additionally, they reported the highest maximal magnetic energy values $(B H)_{\text {max }} 4.0-4.6 \mathrm{~kJ} / \mathrm{m}^{3}$, for the samples with the lowest $\mathrm{Fe}_{3} \mathrm{O}_{4}$ content, underlining the complexity of the involved demagnetization mechanism.

Vázquez-Victorio [67] combined soft chemistry synthesis (polyol process) and consolidation by SPS to produce nanostructured $\mathrm{BaFe}_{12} \mathrm{O}_{19}$ barium hexaferrite. Typically, they produced an intermediate solid phase by reaction of the metallic salts in a polyol within an appropriate $\mathrm{Ba} / \mathrm{Fe}$ atomic ratio; they were annealed at $800^{\circ} \mathrm{C}$ to complete the desired crystalline phase before SPS sintering at $800^{\circ} \mathrm{C}$ for $5-10 \mathrm{~min}$ and $100 \mathrm{MPa}$, under vacuum. Varying the nature of the metallic salts and the polyol solvent, they succeeded to produce highly dense (density $>95 \%)$ and ultrafine-grained $(\sim 100 \mathrm{~nm})$ pure $\mathrm{BaFe}_{12} \mathrm{O}_{19}$ and $\mathrm{BaFe}_{12} \mathrm{O}_{19}$ with a small content of iron oxide. A direct dependency of the magnetic properties of the produced solids on their iron oxide content was observed (Figure 11). The highest coercive field and magnetization 


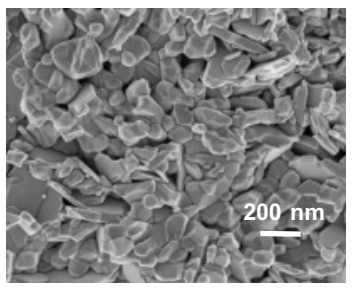

a)

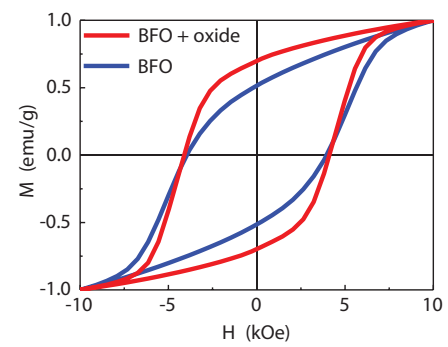

b)

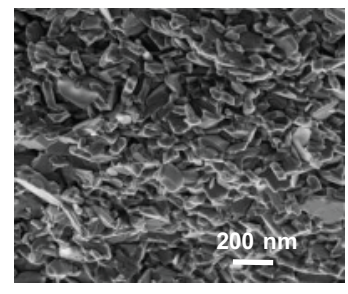

c)

Figure 11. SEM micrographs of (a) $\mathrm{BaFe}_{12} \mathrm{O}_{19}$ and (c) $\mathrm{BaFe}_{12} \mathrm{O}_{19}-\mathrm{Fe}_{2} \mathrm{O}_{3}$ nanostructures produced by combining polyol process to SPS $\left(800^{\circ} \mathrm{C}, 100 \mathrm{MPa}, 5 \mathrm{~min}\right)$, and their room temperature hysteresis loops (b) [67].

at maximum applied field of $1 \mathrm{~T}$ (and hence the energy product $B H$ ) was measured at room temperature, on the nanocomposite. The hysteresis loops also appeared closer to a rectangular form, which is the best shape for applications, as this leads to a well-defined coercive field and remanent magnetization.

\section{Conclusions}

Currently, spark plasma sintering appears as the only method capable to consolidate nanopowders into high-density nanostructured solids; in this chapter, we have briefly reviewed its application to carry out also the solid-state reaction needed to achieve a particular phase, starting from precursors synthesized by diverse methods. Many challenges remain, especially in the cases of reaction by precursor decomposition, when reaction and sintering temperatures are significantly different. RSPS is still a very young technique, with many potential capabilities, which will certainly be developed in the near future.

\section{Author details}

Giulia Franceschin ${ }^{1}$, Nancy Flores-Martínez ${ }^{1}$, Gabriela Vázquez-Victorio ${ }^{1,2}$, Souad Ammar ${ }^{1}$ and Raul Valenzuela ${ }^{1,2 *}$

*Address all correspondence to: monjaras@unam.mx

1 ITODYS, Université Paris Diderot, Sorbonne Paris Cité, Paris Cedex, France

2 Institute for Materials Research, National Autonomous University of Mexico, Mexico City, México 


\section{References}

[1] Anis SF, Khalil A, Saepurahman, Singarave G, Hashaikeh R. A review on the fabrication of zeolite and mesoporous inorganic nanofibers formation for catalytic applications. Microporous \& Mesoporous Materials. 2016;236:176-192. DOI: 10.1016/j. micromeso.2016.08.043

[2] Zeinali-Sehrig F, Majidi S, Asvadi S, Hsanzadeh A, Hossein-Rasta S, Emamverdy M, Akbarzadeh J, Jahangiri S, Farahkhiz S, Akbarzadeh A. An update on clinical applications of magnetic nanoparticles for increasing the resolution of magnetic resonance imaging. Artificial Cells, Nanomedicine and Biotechnology. 2016;44:1583-1588. DOI: 10.3109/21691401.2015.1101001

[3] Kuhl S, Strasser P. Oxygen electrocatalysis on dealloyed Pt nanocatalysts. Topics in Catalysis. 2016;59:1628-1637. DOI: 10.1007/s11244-016-0682-z

[4] Xiao D, Lu T, Zeng R, Bi Y. Preparation and highlighted applications of magnetic microparticles and nanoparticles: A review on recent advances. Microchimica Acta. 2016;183:2655-2675. DOI: 10.1007/s00604-016-1928-y

[5] Guimaraes AP. Principles of Nanomagnetism. Berlin, Heidelberg: Springer-Verlag; 2009. p. 236. DOI: 10.1007/978-3-642-01482-6

[6] Bedanta S, Barman A, Kleemann W, Petracic O, Seki T. Synthesis, properties, and applications of single-domain magnetic nanoparticles. Journal of Nanomaterials. 2013:130180. DOI: $10.1155 / 2013 / 130180$

[7] Thomson T, Hu G, Terris BD. Intrinsic distribution of magnetic anisotropy in thin films probed by patterned nanostructures. Physical Review Letters. 2006;96:257204. DOI: 10.1103/PhysRevLett.96.257204

[8] Orrù R, Licheri R, Locci AM, Cincotti A, Cao G. Consolidation/synthesis of materials by electric current activated/assisted sintering. Materials Science and Engineering Review. 2009;63:127-287. DOI: 10.1016/j.mser.2008.09.003

[9] Guillon O, Gonzalez-Julian J, Dargatz B, Kessel T, Schierning G, Räthel J, Herrmann M. Field-assisted sintering technology/spark plasma sintering: Mechanisms, materials, and technology developments. Advanced Engineering Materials. 2014;16:830-849. DOI: 10.1002/adem.201300409

[10] Garay JE. Current-activated, pressure-assisted densification of materials. Annual Reviews of Materials Science. 2010;40:445-468. DOI: 10.1146/annurev-matsci-07909-104433

[11] Kali R, Mukhopadhyay A. Spark plasma sintered/synthesized dense and nanostructured materials for solid-state Li-ion batteries: Overview and perspective. Journal of Power Sources. 2014;920:920-931. DOI: 10.1016/j.jpowsour.2013.09.010

[12] Regaieg Y, Sicard L, Monnier J, Koubaa M, Ammar-Merah S, Cheikhrouhou A. Magnetic and magnetocaloric properties of $\mathrm{La} 0.85(\mathrm{Na} 1-\mathrm{xKx}) 0.15 \mathrm{MnO} 3$ ceramics produced by 
reactive spark plasma sintering. Journal of Applied Physics. 2014;115:17A917. DOI: $10.1063 / 1.4864138$

[13] Navrotsky A. Energetics of oxide nanoparticles. International Journal of Quantum Chemistry. 2009;109:2647. DOI: 10.1002/qua.21981

[14] Production of sintering components. In: Höganäs Handbook for Sintering Components. 2013. pp. 25-49, Höganäs Ab Laboratories, Sweden. Website: Handbook2_Production_ of_Sintered_Components_December_2013_0675HOG_interactive.pdf

[15] Isobe T, Daimond K, Sato T, Matsubara T, Hikichia Y, Ota T. Spark plasma sintering technique for reaction sintering of $\mathrm{Al}_{2} \mathrm{O}_{3} / \mathrm{Ni}$ nanocomposites and its mechanical properties. Ceramics International. 2008;34:213-217. DOI: 10.1016/j.ceramint.2006.08.017

[16] Available from: http://web.mit.edu/2.813/www/readings/Ellingham_diagrams.pdf

[17] Liu H, Liu L, Ye F, Zhang Z, Yu Z. Microstructure and mechanical properties of the spark plasma sintered $\mathrm{TaC} / \mathrm{SiC}$ composites: Effects of sintering temperatures. Journal of European Ceramics Society. 2012;32:3617-3825. DOI: 10.1016/j.jeurceramsoc.2012.04.042

[18] Monteverde F. Ultra-high temperature $\mathrm{HfB}_{2}-\mathrm{SiC}$ ceramics consolidated by hot-pressing and spark plasma sintering. Journal of Alloys and Compounds. 2007;428:197-205. DOI: 10.1016/j.jallcom.2006.01.107

[19] Sciti D, Bonnefont G, Fantozzi G, Silvestroni L. Spark plasma sintering of $\mathrm{HfB}_{2}$ with low additions of silicides of molybdenum and tantalum. Journal of the European Ceramic Society. 2010;30:3253-3258. DOI: 10.1016/j.jeurceramsoc.2010.06.006

[20] Licheri R, Orrù R, Musa C, Locci AM, Cao G. Consolidation via spark plasma sintering of $\mathrm{HfB}_{2} / \mathrm{SiC}$ and $\mathrm{HfB}_{2} / \mathrm{HfC} / \mathrm{SiC}$ composite powders obtained by self-propagating high-temperature synthesis. Journal of Alloys and Compounds. 2009;478:572-578. DOI: 10.1016/j.jallcom.2008.11.092

[21] Casolco SR, Xu J, Garay JE. Transparent/translucent polycrystalline nanostructured yttria stabilized zirconia with varying colors. Scripta Materalia. 2008;58:516-519. DOI: 10.1016/j.scriptamat.2007.11.014

[22] Ayadi F, Ammar S, Cheikhrouhou-Koubaa W, Cheikhrouhou A, Nowak S, Monnier J, Sicard. Magnetocaloric nanostructured $\mathrm{La}_{0.7} \mathrm{Ca}_{0.3-\mathrm{x}} \mathrm{Ba}_{\mathrm{x}} \mathrm{MnO}_{3}(0<\mathrm{x}<0.3)$ ceramics produced by combining polyol process to spark plasma sintering. Journal of Alloys and Compounds. 2017;691:474-481. DOI: 10.1016/j.jallcom.2016.08.281

[23] Valenzuela R, Gaudisson T, Ammar S. Severe reduction of Ni-Zn ferrites during consolidation by spark plasma sintering (SPS). Journal of Magnetism and Magnetic Materials. 2016;400:311-314. DOI: 10.1016/j.jmmm.2015.07.044

[24] Grasso S, Yoshida H, Porwala H, Sacca Y, Reece M. Highly transparent $\alpha$-alumina obtained by low cost high pressure SPS. Ceramics International. 2013;39:3243-3248. DOI: 10.1016/j.ceramint.2012.10.012 
[25] Weissler GA. Resistance sintering with alumina dies. International Journal of Powder Metallurgy. 1981;17:107

[26] Kamikawa M, Kano Y. JP Patent JP2001226703; 2001

[27] Munir AZ, Anselmi-Tamburini U, Ohyanagi M. The effect of electric field and pressure on the synthesis and consolidation of materials: A review of the spark plasma sintering method. Journal of Materials Science. 2006;41:763-777. DOI: 10.1007/s10853-006-6552-2

[28] Dudina DV, Mukherjee AK. Reactive spark plasma sintering: Successes and challenges of nanomaterial synthesis. Journal of Nanomaterials. 2013:625218. DOI: $10.1155 / 2013 / 625218$

[29] Schmidt J, Niewa R, Schmidt M, Grin Y. Spark plasma sintering effect on the decomposition of $\mathrm{MgH}_{2}$. Journal of the American Ceramic Society. 2005;88:1870-1874. DOI: 10.1111/j.1551-2916.2005.00358.x

[30] Skandan G, Hahn H, Kear BH, Roddy M, Cannon WR. The effect of applied stress on densification of nanostructured zirconia during sinter-forging. Materials Letters. 1994;20:305. SSDI: 0167-577x(94)00114-3

[31] Chen XJ, Khor KA, Chan SH, Yu LG. Overcoming the effect of contaminant in solid oxide fuel (SOFC) electrolyte: Spark plasma sintering (SPS) of $0.5 \mathrm{wt} \%$ silica-doped yttria-stabilized zirconia (YSZ). Materials Science and Engineering A. 2004;374:64-71. DOI: 10.1016/j.msea.2003.12.028

[32] Nygren M. SPS processing of nano-structured ceramics. Journal of Iron and Steel Research, International. 2007;14:99-103. DOI: 10.1016/S1006-706X(08)60060-6

[33] Diouf S, Molinari A. Densification mechanisms in spark plasma sintering: Effect of particle size and pressure. Powder Technology. 2012;221:220-227. DOI: 10.1016/j. powtec.2012.01.005

[34] Stanciu L, Groza JR, Stoica L, Plapcianu C. Influence of powder precursors on reaction sintering of $\mathrm{Al}_{2} \mathrm{TiO}_{5}$. Scripta Materialia. 2004;50:1259-1262. DOI: 10.1016/j. scriptamat.2004.01.034

[35] Gaudisson T, Artus M, Acevedo U, Herbst F, Nowak S, Valenzuela R, Ammar S. On the microstructural and magnetic properties of fine-grained $\mathrm{CoFe}_{2} \mathrm{O}_{4}$ ceramics produced by combining polyol process and spark plasma sintering. Journal of Magnetism and Magnetic Materials. 2014;370:87-95. DOI: 10.1016/j.jmmm.2014.06.014

[36] Munir ZA. Synthesis and densification of nanomaterials by mechanical and field activation. Journal of Materials Synthesis and Processing. 2000;8:189-196. DOI: 10.1023/A:1011312126285

[37] Zhang HW, Gopalan R, Mukai T, Hono K. Corrigendum to "Fabrication of bulk nanocrystalline Fe-C alloys by spark plasma sintering of mechanically milled powder" [Scripta Materialia 2005; 53: 863-868]. Scripta Materialia. 2005;54:1827-1828. DOI: 10.1016/j.scriptamat.2006.02.001 
[38] Locci AM, Orrù R, Cao G, Munir ZA. Effect of ball milling on simultaneous spark plasma synthesis and densification of $\mathrm{TiC}-\mathrm{TiB}_{2}$ composites. Ceramics International. 2006;434:2329. DOI: 10.1016/j.msea.2006.06.131

[39] Cullity BD. Introduction to Magnetic Materials. California: Addison-Wesley Publishing Company; 1972

[40] Song S, Song Q, Li J, Mudinepalli VR, Zhang Z. Characterization of submicrometer-sized NiZn ferrite prepared by spark plasma sintering. Ceramics International. 2014;40:64736479. DOI: 10.1016/j.ceramint.2013.11.099

[41] Zehani K, Ahmadi B, Loyau V, Champion Y, Bessais L, Lobue M, Labouré E, Mazaleyrat F. Structural, dielectric, and magnetic properties of $\mathrm{NiZnCu}$ ferrites synthesized by reactive spark plasma sintering process. IEEE Transactions on Magnetics. 2014;50:1-4. DOI: 0.1109/TMAG.2013.2284766

[42] Regaieg Y, Delazair G, Herbst F, Sicard L, Monnier J, Montero D, Villeroy B, Koubaa M, Ammar S, Cheikhrouhou A, Godart C. Fast reactivity by spark plasma sintering: The case of orthorhombic $\mathrm{LaMnO}_{3}$ compound. Material Letters. 2012;80:195-198. DOI: 10.1016/j.matlet.2012.04.046

[43] Abdallah Ben Ammar A, Ayadi F, Nowak S, Lecoq H, Cheikrouhou-Koubaa W, Cheikhrouhou A, Ammar S, Sicard L. A combined sol-gel and spark plasma sintering route to produce highly dense and fine-grained $\mathrm{La}_{0.65} \mathrm{Ca}_{0.20} \mathrm{Na}_{0.15} \mathrm{MnO}_{3}$ ceramics for magnetocaloric applications. Materials Research Express. 2014;1:015703. DOI: 10.1088/2053-1591/1/1/015703

[44] Mo N, Green JJ, Beitscher BA, Patton CE. High precision-metrology based microwave effective line width measurement technique. Review of Scientific Instruments. 2007;78:113903. DOI: $10.1063 / 1.2813344$

[45] Stadler BJH, Mizumoto T. Integrated magneto-optical materials and isolators. IEEE Photonics Journal. 2013;6:0600215. DOI: 10.1109/JPHOT.2013.2293618

[46] Hyde P, Bai L, Kumar DMJ, Southern BW, Hu C-M, Huang SY, Miao BF, Chien CL. Electrical detection of direct and alternating spin current injected from a ferromagnetic insulator into a ferromagnetic metal. Physical Review B. 2014;89:180404. DOI: 10.1103/ PhysRevB.89.180404

[47] Niyaifar Ramani M, Radhakrishna MC, Hasapour A, Mozaffari M, Amighian J. Magnetic studies of $\mathrm{Bi}_{x} \mathrm{Y}_{3-x} \mathrm{Fe}_{5} \mathrm{O}_{12}$ fabricated using conventional method. Hyperfine Interactions. 2008;187:137-141. DOI: 10.1007/s10751-008-9875-6

[48] Sánchez-De Jesús F, Cortés CA, Valenzuela R, Ammar S, Bolarín-Miró AM. Synthesis of $\mathrm{Y}_{3} \mathrm{Fe}_{5} \mathrm{O}_{12}(\mathrm{YIG})$ assisted by high-energy ball milling. Ceramics International. 2012;38:52575263. DOI: 10.1016/j.ceramint.2012.03.036

[49] Gaudisson T, Acevedo U, Nowak S, Yaacoub N, Greneche J-M, Ammar S, Valenzuela $\mathrm{R}$. Combining soft chemistry and spark plasma sintering to produce highly dense and finely grained soft ferrimagnetic $\mathrm{Y}_{3} \mathrm{Fe}_{5} \mathrm{O}_{12}$ (YIG) ceramics. Journal of the American Ceramic Society. 2013;96:3094-3099. DOI: 10.1111/jace.12452 
[50] Jin S, Tiefel TH, McCormack M, Fastnacht RA, Ramesh R, Chen LH. Thousand fold change in resistivity in magnetoresistive La-Ca-Mn-O films. Science. 1994;264:413-415. DOI: $10.1126 /$ science.264.5157.413

[51] Yunoki S, Hu J, Malvezzi AL, Moreo A, Furukawa N, Dagotto E. Phase separation in electronic models for manganites. Physical Review Letters. 1998;80:845. DOI: 10.1103/ PhysRevLett.80.845

[52] Salamon MB, Jaime M. The physics of manganites: Structure and transport. Reviews of Modern Physics. 2001;73:583. DOI: 10.1103/RevModPhys.73.583

[53] Phan M-H, Yu S-C. Review of the magnetocaloric effect in manganite materials. Journal of Magnetism and Magnetic Materials. 2007;308:325-340. DOI: 10.1016/j.jmmm.2006.07.025

[54] Zener N. Interaction between the d-shells in the transition metals. II. Ferromagnetic compounds of manganese with perovskite structure. Physical Review. 1951;82:403. DOI: /10.1103/PhysRev.82.403

[55] Goodenough JB. Theory of the role of covalence in the perovskite-type manganites [La,M(II)]MnO ${ }_{3}$. Physical Review. 1955;100:564. DOI: 10.1103/PhysRev.100.564

[56] Topfer J, Goodenough JB. Journal of Solid State Chemistry. $\mathrm{LaMnO}_{3-\delta}$ Revisited. 1997;130:117-128. DOI: 10.1006/jssc.1997.7287

[57] Regaieg Y, Sicard L, Monnier J, Delaizir G, Koubaa M, Godart C, Ammar-Merah S, Cheikhrouhou A. Rapid synthesis of $\mathrm{La}_{0.85} \mathrm{Na}_{0.15} \mathrm{MnO}_{3}$ by spark plasma sintering: Magnetic and magnetocaloric study. Materials Chemistry and Physics. 2013;139:629633. DOI: 10.1016/j.matchemphys.2013.02.008

[58] Regaieg Y, Ayadi F, Nowak S, Koubaa M, Cheikhrouhou A, Reguer S, Monnier J, Sicard $\mathrm{L}$, Ammar-Merah S. Magnetocaloric properties of $\mathrm{La}_{0.67} \mathrm{Ca}_{0.33} \mathrm{MnO}_{3}$ produced by reactive spark plasma sintering and by conventional ceramic route. Material Research Express. 2014;1:046105. DOI: 10.1088/2053-1591/1/4/046105

[59] Ayadi F. Approche couplée de synthèse par chimie douce et SPS de manganites substitués pour la réfrigération magnétique [joint $\mathrm{PhD}$ thesis]. France and Tunisia: Paris Diderot University and University of Sfax; 2014

[60] Pullar RC. Hexagonal ferrites: A review of the synthesis, properties and applications of hexaferrite ceramics. Progress in Materials Science. 2012;57:1191-1334. DOI: 10.1016/j. pmatsci.2012.04.001

[61] Jamalian M. An investigation of structural, magnetic and microwave properties of strontium hexaferrite nanoparticles prepared by a sol-gel process with doping SN and Tb. Journal of Magnetism and Magnetic Materials. 2015;378:217-220. DOI: 10.1016/j. jmmm.2014.11.047

[62] Drofenik M, Ban I, Makovec D, Žnidaršič A, Jagličić Z, Hanžel D, Lisjak D. The hydrothermal synthesis of super-paramagnetic barium hexaferrite particles. Materials Chemistry and Physics. 2011;127:415-419. DOI: 10.1016/j.matchemphys.2011.02.037 
[63] González-Carreňo T, Morales MP, Serna CJ. Barium ferrite nanoparticles prepared directly by aerosol pyrolysis. Materials Letters. 2000;43:97-101. DOI: 10.1016/ S0167-577X(99)00238-4

[64] Sánchez-De Jesús F, Bolarín-Miró AM, Cortés-Escobedo CA, Valenzuela R, Ammar S. Mechanosynthesis, crystal structure and magnetic characterization of M-type $\operatorname{SrFe}_{12} \mathrm{O}_{19}$. Ceramics International. 2014;40:4033-4038. DOI: 10.1016/j.ceramint.2013.08.056

[65] Bolarín-Miró AM, Sánchez-De Jesús F, Cortés-Escobedo CA, Díaz-De la Torre S, Valenzuela R. Synthesis of M-type $\mathrm{SrFe}_{12} \mathrm{O}_{19}$ by mechanosynthesis assisted by spark plasma sintering. Journal of Alloys and Compounds. 2015;643:S226-S230. DOI: 10.1016/j. jallcom.2014.11.124

[66] Stingaciu M, Topole M, McGuiness P, Christensen M. Magnetic properties of ballmilled $\mathrm{SrFe}_{12} \mathrm{O}_{19}$ particles consolidated by spark-plasma sintering. Scientific Reports. 2015;5:14112. DOI: 10.1038/srep14112

[67] Vázquez-Victorio G. Ferritas nanoestructuradas, síntesis y propiedades magnéticas [PhD thesis]. Universidad Nacional Autónoma de Mexico (UNAM); 2017 
